\title{
ReaR
}

\section{Valoración y Manejo de la Vía Aérea en Paciente con Enfermedad COVID-19}

Navarro G (1), Sandoval C (2), Quintero K (3), Pérez L (4).

(1) Coordinador del Capítulo de Vía Aérea Difícil de la Confederación Latinoamericana de Sociedades de Anestesia (CLASA).

(2) Hospital Ángeles León, México

(3) Complejo Hospitalario Metropolitano Dr. Arnulfo Arias Madrid, Panamá

(4) Hospital San Juan de Dios, San José, Costa Rica

\section{Resumen}

En la mayor crisis mundial de salud contemporánea de la que se tiene memoria, todos tienen miles de preguntas por hacer, pero nadie tiene las respuestas correctas para dar, esto será un mundo dinámico, agudo, de cambios, aprendizajes, experiencias y reaprendizajes constantes que tendremos que estar dispuestos a afrontar y absorber en un camino plagado de grises y sombras. La cantidad y calidad de información vertida en relación a la valoración y tratamiento VA en pacientes sospechados o contaminados $\mathrm{C} 19$, ha alcanzado una magnitud tan impresionante como la propia diseminación del virus. Existe material de excelente calidad informativa en video tutoriales, esquemas, algoritmos, ayudas visuales, documentos, publicaciones online, etc., pero también se ha dispersado una cantidad no menor de información que es incorrecta y de mala calidad.

\section{Introducción}

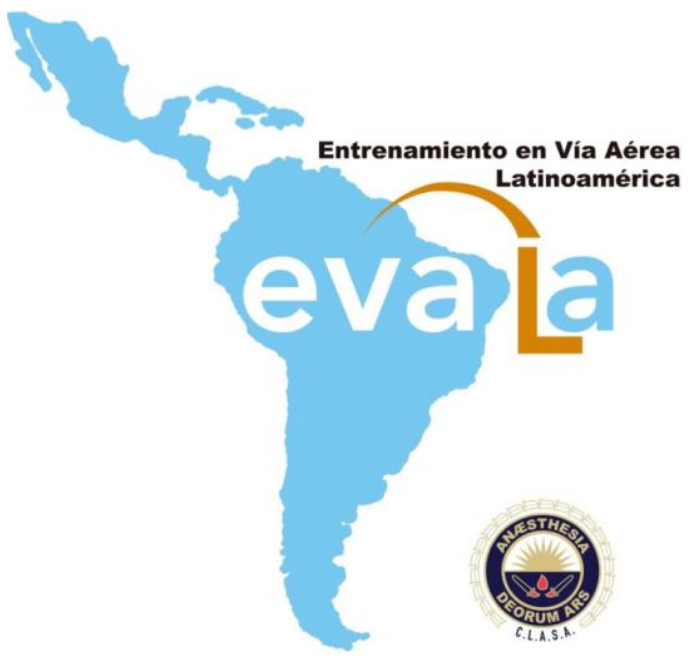

En la mayor crisis mundial de salud contemporánea de la que se tiene memoria, todos tienen miles de preguntas por hacer, pero nadie tiene las respuestas correctas para dar, esto será un mundo dinámico, agudo, de cambios, aprendizajes,

experiencias $\mathrm{y}$ reaprendizajes constantes que tendremos que estar dispuestos a afrontar y absorber en un camino plagado de grises y sombras. La cantidad y calidad de información vertida en relación a la valoración y tratamiento VA en pacientes sospechados o contaminados C19, ha alcanzado una magnitud tan impresionante como la propia diseminación del virus. Existe material de excelente calidad informativa en video tutoriales, esquemas, algoritmos, ayudas visuales, documentos, publicaciones online, etc., pero también se ha dispersado una cantidad no menor de información que es incorrecta y de mala calidad.

\section{Índice}

1. Introducción

2. Fuentes Consultadas 
3. Definiciones y términos para comprender el alcance de lo que se está leyendo.

4. Seguridad del personal de salud, riesgo de contaminación durante el manejo de la vía aérea

5. Quién/quiénes podrían ser parte de un C19. 24/7 Airway Team

6. Preparación para el manejo de la vía áerea

7. Intubación (Parte II)

8. Extubación (Parte II)

9. Resumen y puntos claves (Parte II)

10. Referencias (Parte II)

\section{Introducción}

En la mayor crisis mundial de salud contemporánea de la que se tiene memoria, todos tienen miles de preguntas por hacer, pero nadie tiene las respuestas correctas para dar, esto será un mundo dinámico, agudo, de cambios, aprendizajes, experiencias y reaprendizajes constantes que tendremos que estar dispuestos a afrontar $y$ absorber en un camino plagado de grises y sombras.

La cantidad y calidad de información vertida en relación a la valoración y tratamiento VA en pacientes sospechados o contaminados $\mathrm{C} 19$, ha alcanzado una magnitud tan impresionante como la propia diseminación del virus. Existe material de excelente calidad informativa en video tutoriales, esquemas, algoritmos, ayudas visuales, documentos, publicaciones online, etc., pero también se ha dispersado una cantidad no menor de información que es incorrecta y de mala calidad.

Es necesario confirmar las fuentes desde donde se va adoptará la información, para garantizar que la misma sea una ayuda objetiva a los diferentes prestadores y operadores sobre todo enfocados en:
-Control de las infecciones y contaminación del personal de salud (relacionados a los equipos de protección personal (EPP).

- Uso racional y adecuado de insumos y tratamiento del ambiente

-La oportunidad terapéutica para cada paciente en particular

\section{Fuentes consultadas}

Para la confección de este documento se han revisado diversas fuentes que han reunido al menos una de dos condiciones esenciales para la obtención de información calificada: primero, la información está vertida desde sociedades científicas internacionales de prestigio mundial en temas relacionados al control de la VA, segundo, los autores han sido partícipes primarios de las experiencias vividas en la contención $\mathrm{y}$ el tratamiento de anteriores y de la actual pandemia. Estas condiciones han permitido a los expertos declarar una serie de recomendaciones que sin pretender hacer de ellas un estándar de cuidados, son de máxima utilidad para diseñar estrategias locales de contención adaptadas a las posibilidades logísticas y económicas de cada región.

\section{Definiciones y Términos}

Es importante comprender técnicamente algunos términos y definiciones para una correcta interpretación de la lectura.

\section{Estándar de cuidados:}

-Principios aceptados para el manejo del paciente, cuyos fallos $\mathrm{u}$ omisiones son muy difíciles de justificar (carácter mandatorio). 


\section{Estrategia:}

-Serie de pasos escalonados para conseguir un objetivo (carácter no mandatorio).

\section{Guías:}

-Herramientas de capacitación con desarrollo sistemático de contenidos para asistir a los médicos en circunstancias clínicas puntuales, incluyendo la mejor evidencia científica disponible y la opinión de los expertos. (carácter no mandatorio)

\section{Recomendaciones:}

-Estrategias disponibles pero sin la rigurosidad de los estándares y las guías. (carácter no mandatorio)

\section{Protocolos y Algoritmos:}

-Procedimientos o pasos en árbol de decisiones a través del diagnóstico y tratamiento de escenarios clínicos. (carácter no mandatorio)

\section{Lista de Chequeo o lista de verificación:}

Formatos para controlar el cumpli miento de determinadas intervencio nes pre asignadas

\section{Ayudas visuales:}

- Herramienta de implementación que trata de expresar un concepto, una idea, a través de imágenes.

Este y otros documentos similares están presentando "series de recomendaciones" basadas en experiencias previas de colegas como tales, las mismas no son de carácter mandatorio, sino voluntario, y sujetas a adaptaciones según disponibilidad, logística e interpretación regional. Es importante comprender este concepto desde un punto de vista técnico, ya que las diferentes opiniones de los profesionales son extremadamente comunes en este contexto. Sin embargo las recomendaciones pueden convertirse en un diagrama orientador de gran importancia.

\section{Seguridad del personal de salud y riesgo de contaminación durante el manejo de la vía aérea}

La intervención sobre la vía aérea en sus diferentes formas, conlleva un riesgo de contaminación al personal de salud, generalmente bajo y de ocurrencia extraña. Sin embargo en situaciones especiales como la que nos toca vivir prácticamente en todo el mundo hoy afectado por $\mathrm{C} 19$, los recaudos podrían cambiar sustancialmente debido a que la contaminación del personal expuesto, deteriora la capacidad prestacional del sistema y aumenta el número global de casos. Una ecuación que claramente aporta un efecto negativo y por ende es muy importante prevenir.

Los estudios disponibles sobre este tema son escasos y sistema de clasificación de la calidad de la evidencia y graduación de la fuerza de la recomendación (GRADE) los califica como muy bajos. En la epidemia de SARS, el $21 \%$ de los infectados globales fueron los mismos trabajadores de la salud. En Canadá sobre una cuenta final de contaminados por SARS de 245 individuos, el $43 \%$ del total fueron trabajadores de la de salud mayoritariamente de Toronto. Esto generó en su momento gran preocupación, porque a pesar de que "idealmente" se había instruido y entrenado al personal para la utilización correcta del EPI (equipo de protección individual) los incidentes ocurrieron igual. Un posterior análisis de esto, dejó aprendizajes interesantes. 
La protección de los trabajadores de la salud, no dependería exclusivamente del uso del EPP, si no que también abarca principios importantes adicionales de control de infecciones. En diferentes áreas donde los pacientes enfermos de SARS fueron tratados, departamentos de emergencia (DE), unidades de cuidados críticos (UCC), hubo situaciones de falta de control caracterizadas por múltiples oportunidades de contaminación hacia el personal de salud, previo al evento de la IOT propiamente. Los prestadores habían estado en riesgo de contaminación antes de la instalación de los EPI, lo que pudo expresar una falta de triage temprano y aislamiento inmediato de los casos de sospecha. Otras condiciones del ambiente podrían haber influido negativamente también.

Una investigación post SARS a los trabajadores de la de salud, reveló una falta de compromiso o uso subóptimo de los EPI. Aunque se conoce poco del C19, se cree con alguna fortaleza que se propaga de persona a persona, entre personas a través de gotitas respiratorias y transmisión por contacto cercano. La protección con una bata o vestido impermeable, asimismo de los ojos, el rostro, los guantes dobles son altamente efectivos en estos casos de intervención donde las gotitas y contactos son tan influyentes en una contaminación.

En este último episodio de C19 se han reportado casos de contaminación del personal en los hospitales de Wuhan (China) tras las intervenciones de IOT. Se desconoce con exactitud el nivel de contaminación que dicho grupo ocupacionalmente expuesto podría estar padeciendo durante la atención de pacientes en esta pandemia, pero hay informes preliminares estimando que en algunos países podrían alcanzar hasta el $20 \%$ del global.
La Organización Mundial de la Salud (OMS) y el Centro para el Control de Enfermedades (Center for Disease Control [CDC]) y los sistemas de guías de prevención para la protección del personal durante procedimientos $\mathrm{o}$ intervenciones clínicas de riesgo en pacientes sospechados o confirmados de C19, se enfocan en:

--Posibilidades de dispersión viral

--Principios de una comunicación clara

--Minimizar la cantidad de personal durante la intervención

--Utilización apropiada de los EPP en todos los casos

--Evitar procedimientos

--Tratamiento adecuado (descontaminación y desinfección) de los ambientes utilizados para la intervención

Estas comunicaciones no pretenden ser obligatorias y cada hospital deberá desarrollar planes locales desde sus posibilidades logísticas, económicas y de recursos disponibles a través de una:

-Generación de procedimiento médico de sospecha/confirmación de pacient e C19 y adecuación de espacios.

-Interacción operativa entre departam entos de emergencias, unidades de c uidados críticos, servicios de anestesiología y reanimación, terapia respiratoria, unidad de control de infecciones, salud ocupacional, entre otros.

Además del EPP, son fundamentales los procedimientos de descontaminación de superficies y equipos, minimizar la exposición de personal no esencial durante actividades de riesgo como la intubación orotraqueal (IOT), correcto 
manejo de los insumos y residuos, y la posterior limpieza del/los ambientes (al menos 20 a 30 minutos tras el último procedimiento generador de aerosoles).

\section{Quién/Quiénes podrían conformar un Airway Team 24/7}

Esta es una planificación que podría variar en cada región y aún dentro de un mismo país, en cada hospital o prestador. Por razones lógicas de la enfermedad, la primera línea recaería sobre los DE y UCC que en algunos países son comandados por los mismos anestesiólogos y especialistas en manejo de la unidades de dolor agudo y crónico. Sin embargo si bien nuestras realidades en lo que a práctica clínica refiere son diferentes, se pueden o no tomar algunas ideas de programación para hospitales públicos y o servicios de anestesia privados locales.

Por citar un ejemplo, algunos centros organizan un "teamwork 24/7", repartido en tres turnos diarios conformados por dos expertos en VA por turno:

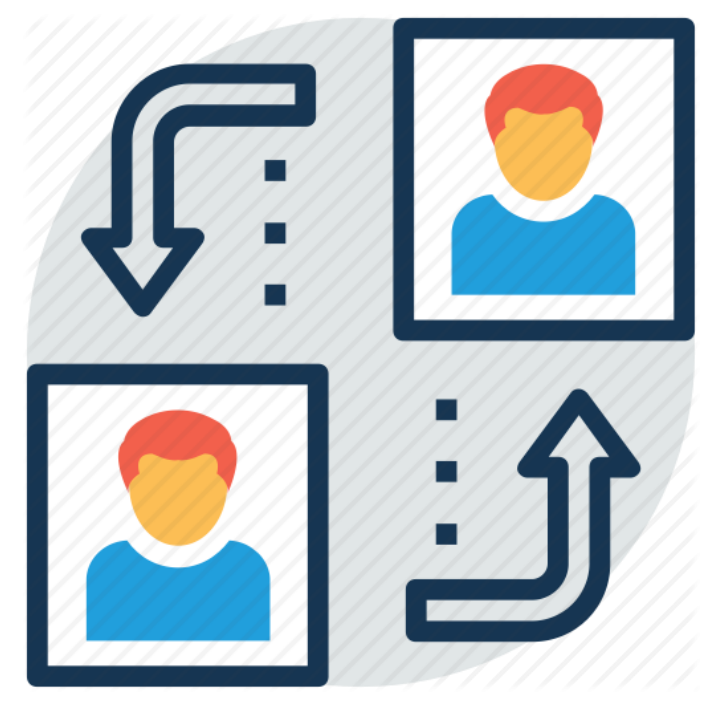

$7 \mathrm{am}-3 \mathrm{pm}$

$3 \mathrm{pm}-11 \mathrm{pm}$

$11 \mathrm{pm}-7 \mathrm{am}$
Bajo este modelo denominado The single C19 Airway Service, se espera al menos desde un punto de vista teórico:

--Minimizar la exposición y el riesgo a los proveedores de salud, al no exponer a todo el personal contratado, pudiéndose asignar recurso humano a otras áreas de cobertura.

-Optimizar la ejecución de los protoc olos, un teamwork pequeño es más $f$ ácil de entrenar y practicar simulación clínica que un grupo grande y variado de personas.

-Incrementar la uniformidad de res ultados (intervenciones con personal de alta competencia, menos complicaciones, menos tiempo de pacientes ventilados, que puede impactar en un menor tiempo de uso de las UCC y de mejoras en los resultados finales).

-Optimización de equipos y recurs os de control e inventarios. El te amwork es responsable del kit de VA, esto puede tener importancia por la descentralización de las intervenciones del departamento de UCC.

-Oportunidad de implementar triages en situaciones de "cuello de botella.

-Oportunidad de aprendizaje y rediseño constante de protocolos de acción a través de feed--back entre grupos pequeños.

-Oportunidad de recopilación de dato $s$ prospectivos de calidad para una e ventual difusión posterior o confección de trials.

-Obtención de datos para el conocim iento a largo plazo, impactos sobre múltiples intentos y mortalidad, tiempos de ventilación requerida y medidas de la mortalidad real. 
Otros hospitales públicos por ejemplo en UK, Nueva Zelanda, han designado a un anestesiólogo líder de VA para cada hospital, quien diseña $\mathrm{y}$ dirije las acciones necesarias para resolver los problemas relacionados a este tópico y otros relacionados al control de la VA en general.

Existen otras propuestas como la asignacion de un "Hospital C19 exclusivo" con la idea de centralizar recursos y aminorar las tasas de contaminación.

Tal como se mencionó anteriormente, cada región y dentro de ella cada hospital, deberá revisar sus mejores opciones de preparación y prestación, más allá de los modelos enunciados arriba.

\section{Preparación para el manejo de la vía aérea}

Procesos de la VA que cursan con riesgo de dispersión viral

Los procedimientos en VA pueden generar aerosoles que incrementan el riesgo dispersión viral y de transmisión de la enfermedad al médico. Las intervenciones más comunes que se espera en pacientes $\mathrm{C} 19+$ son la IOT y la ventilación mecánica (VM). Existen otros tratamientos que pueden requerir los pacientes, ej: intervenciones quirúrgicas de urgencia, trauma, hemorragia, entre otros, quienes finalmente podrían ser $\mathrm{C} 19+$, y que tendrán muy posiblemente que ser intubados/extubados. Este fenómeno claramente podría explicar que las medidas de seguridad deberán tomarse sistemáticamente para el cuidado seguro del personal de salud y los pacientes en todos los casos de intervención.

\section{Ranking de potencial contaminación en orden decreciente}

De alto riesgo:

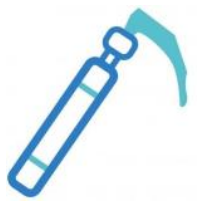

--Intubación oro--traqueal (IOT)

-Accesos infraglóticos (traqueostomía -eFONA-- etc)

-Ventilación no invasiva (VIN)

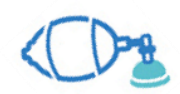

-Ventilación con mascara facial simple (MFS)

Otras intervenciones potencialmente contaminantes incluyen:

-Desconexión del circuito durante el uso

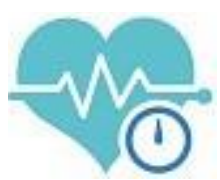

Extubación

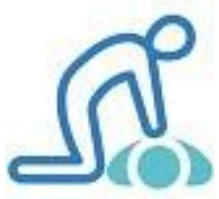

--Reanimación

cardio--pulmonar

(antes de la IOT)

--Broncoscopía 
--Aspiración en sistemas no cerrados

Posiblemente los pacientes severamente enfermos y con mayor carga viral son a la vez candidatos a ser intervenidos con medidas más agresivas y serían quienes podrían tener un nivel de dispersión mayor.

\section{Indicaciones de IOT en pacientes C19+}

\section{Prestar especial atención al desarrollo de:}

-Disnea

-Taquipnea (igual o mayor de 30 respiraciones $x$ minuto)

-Desaturación arterial de $\mathrm{O}_{2}$ menor o igual a $93 \%$.

-Relación $\mathrm{PaO}_{2} / \mathrm{FiO}_{2}$ menor o igual a 300

-Infiltrado pulmonar igual o mayor a $50 \%$ dentro de las 48 horas

\section{Indicaciones absolutas}

-Paro cardio-respiratorio

-Pérdida o amenaza de la permeabilidad de la VA

\section{Indicaciones a discreción del equipo tratante (empírico)}

-Fallo respiratorio agudo hipoxémico

-Presencia sostenida de más de 30 respiraciones por minuto

-Relación $\mathrm{PaO}_{2} / \mathrm{FiO}_{2}$ menor o igual a 150

-Fracaso del alivio tras dos horas de modos no invasivo de sostén (HFNO)
4. Razones para no retardar la indicación de IOT (electivo vs urgencia)

-Indicar la IOT como un proceso proactivo más que de salvataje

- Mejora las condiciones de preparación del ambiente y el personal de salud

-Atenúa el nivel de complicaciones derivadas de la intervención

-Prevención de la hipoxemia silente (asintomática)

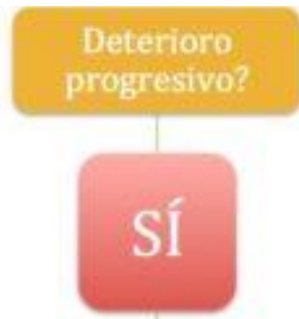

Método de oxigenación

efectivo en las últimas 2 hrs

\section{NO}

\section{INTUBACIÓN}

5. La Intubación pro--activa podría ser útil:

-Se espera un agotamiento de las reservas de $\mathrm{O}_{2}$ en este grupo y mecanismos de compensación exhaustos, que podría atenuarse utilizando escalas de intubación temprana.

-La posibilidad de desaturación arterial precoz después de eliminar la ventilación es mayor y se podría requerir el rescate con máscara aumentando el riesgo de contaminación del procedimiento. 
-La valoración previa podría ser escasa y hasta imposible debido a los controles

estrictos de infección

- EPI escalado a nivel III, podría hacer a los operadores más torpes.

-El control estricto de infecciones y tráfico podría deteriorar la administración de

insumos $y$ ayudantes cuando son necesarios.

-Factores psicológicos (temor a contaminarse) podría hacer fallar al personal aún en

situaciones simples de intervención.

La precaución en el control de infecciones al profesional es de máxima prioridad durante la IOT de pacientes C19. Es un procedimiento de alto riesgo para el profesional y si el paciente está comprometido será de alto riesgo para ambos.

Secreciones, sangre y aerosoles pueden diseminarse ampliamente en el ambiente. Idealmente la intervención debe llevarse adelante en salas especiales (según disponibilidad). Los operadores involucrados deben aplicarse equipos de protección personal (EPP) y seguir las técnicas de colocación y extracción indicada por los especialistas en seguridad.

Deben balancearse los riesgos/beneficios entre modos de administración de $\mathrm{O}_{2}$ (VNI) que pueden ocasionar dispersión viral contra la indicación de una IOT temprana.

\section{Preparación del paciente y la sala de procedimientos}

Llevar un paciente sospechoso/probable/confirmado C19+ requiere de una preparación organizacional, individual y situacional específica, para maximizar la seguridad del procedimiento sobre el paciente y evitar la contaminación del personal que atiende, por lo que alertar al equipo de respuesta con antelación cobra mayor importancia en el abordaje de estos pacientes.

Se alienta fuertemente que el paciente sea previamente valorado por expertos en la búsqueda de señales de dificultad que permitan una planificación previa de ideas y recursos adecuados.

Se alienta fuertemente que el paciente sea previamente valorado por expertos en la búsqueda de señales de dificultad que permitan una planificación previa de ideas y recursos adecuados. La valoración previa de la VA es importante porque se considera la base de la construcción de la estrategia y los planes a seguir.

El equipo de atención debe comunicar claramente la idea del procedimiento y definir los planes alternativos antes del ingreso a la sala de instrumentación.

Se pueden realizar los test de dificultad habituales.

-Historia de dificultad previa

-Distancia entre incisivos menor a $3 \mathrm{~cm}$

-Distancia tiromentoniana menor a 6 $\mathrm{cm}$ o esternomentoniana menor a $12 \mathrm{~cm}$

-Movilidad cervical

-Perímetro cervical

Test de Mallampati está desaconsejado para este grupo de pacientes

Reconocer que los datos de los test son muy importantes, pero no son concluyentes, se debe planificar y 
practicar una estrategia relacionada a un episodio de VA difícil inesperada o de ISRm fallida.

Se recomiendan las siguientes medidas de precaución según disponibilidad local.

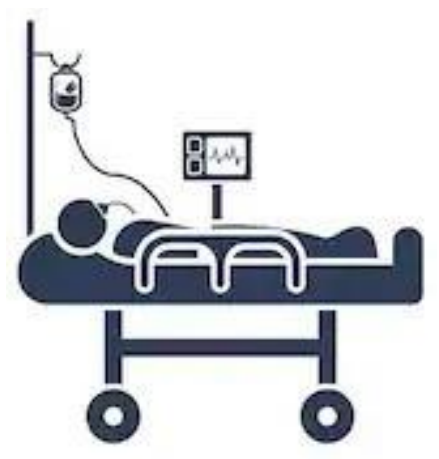

-La habitación debería ser adaptada para instrumentacion clínica de procesos con dispersión viral (generadores de aerosoles) fuera de quirófano $\mathrm{y}$ con presión negativa $\mathrm{y}$ aislamiento de aire (si está disponible).

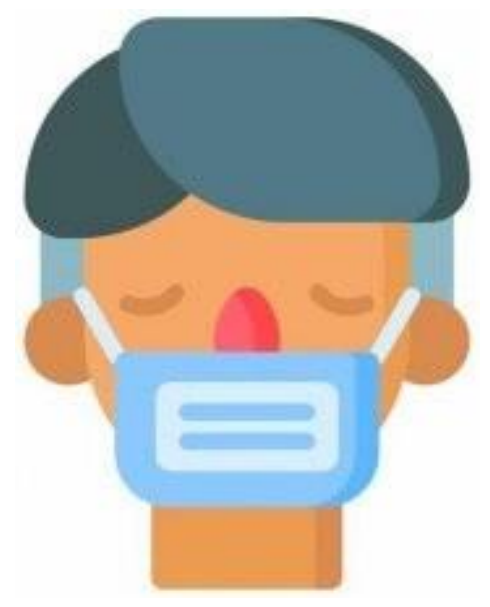

--El paciente debe ser transportado con una mascarilla facial hacia la sala de intervenciones y durante el período previo a la IOT su cara puede ser cubierta con gasas húmedas para evitar la dispersión de secreciones.
--Se puede aportar oxígeno suplementario nasal a bajo flujo si la condición clínica del paciente lo requiere y si está disponible.

--El equipo de atención involucrado en la intervención debe colocarse el EPP o sistemas de protección C19 derivados de las políticas locales de su hospital.
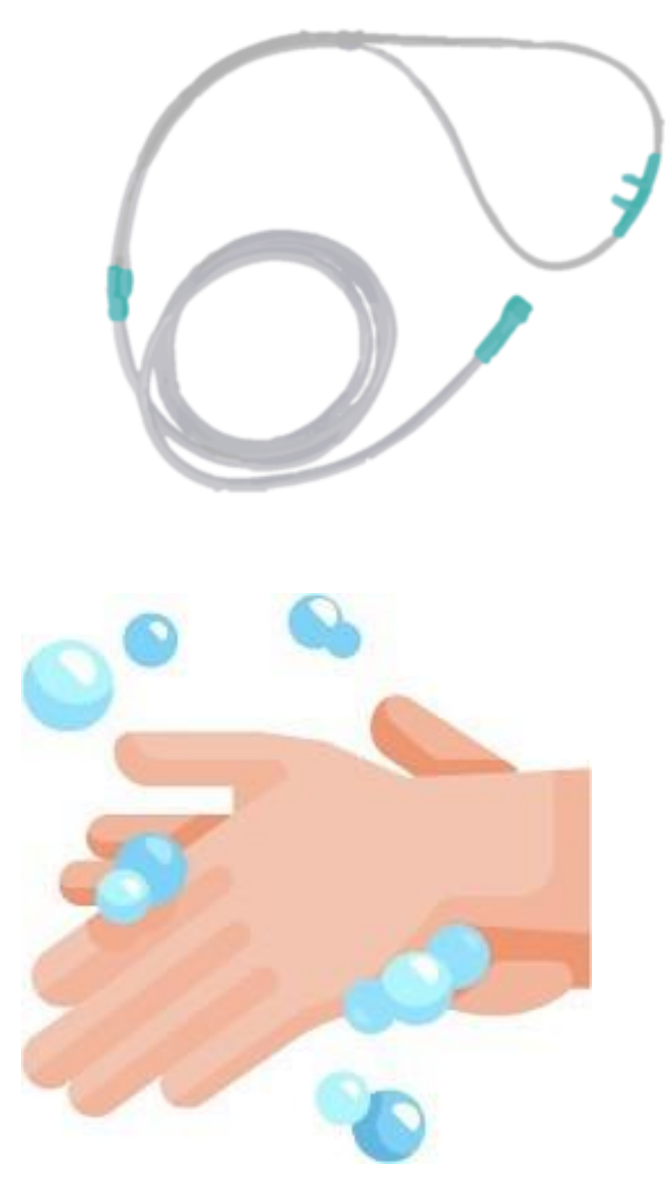

-El lavado adecuado de manos es ob ligatorio antes y después de cualquie $r$ contacto con el paciente, particularmente antes y durante la colocación del EPP y nuevamente después al removerse el EPP. 
--El personal involucrado debe ser mínimo y deben evitarse intercambios de personas a no ser que sea estrictamente necesario durante la intervención.

Las consideraciones particulares sobre la colocación y remoción del EPP pueden revisarse en el video desarrollado por el Servicio de Anestesia y Reanimación del Hospital Universitario Marqués de Valdecilla y realizado en el Hospital Virtual Valdecilla asi como el folleto de la OMS para utilización de equipos de seguridad y protección personal para no extender la redacción del documento.

\section{Carro para manejo de Vía Aérea}

Un carro de VA específicamente diseñado para atender pacientes $\mathrm{C} 19+$ podría ser de gran ayuda en las UCC o en cualquier sitio del hospital, en su ausencia equipo portátil de uso exclusivo para abordar la VA en las unidades de aislamiento de pacientes C19+.

Existen diversas propuestas de carros de VA. El personal que atiende deberá organizar y adecuar según sus posibilidades y recursos locales entre varios modelos disponibles.

www.ccam.net.au/airway-trolley/

https://das.uk.com/content/difficult_air way trolley

\section{http://vortexapproach.org/airwaycart}

\section{Equipo básico}

Se sugiere la disponibilidad de un equipo básico en cualquier escenario en el cual se requiere manejo invasivo de la vía aérea, ya sea en el carro de vía aérea o bien portátil:

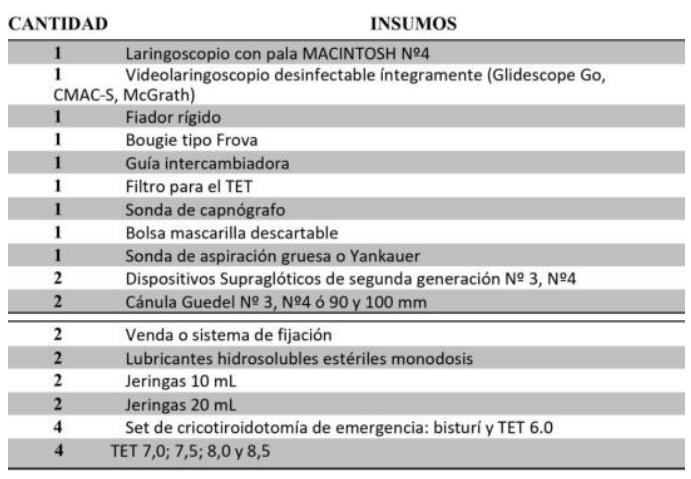

\section{Intubación: "El primer intento es el mejor intento"}

Para garantizar una dispersión mínima de partículas virales durante la intervención definitiva de la VA (IOT), debemos seguir los siguientes pasos:

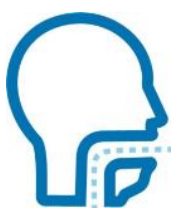

\section{Recursos y equipamiento}

Deben estar preparados de antemano fuera de la sala de intervenciones y disponibles, a la demanda del que realiza la IOT, todo el personal debe conocer los planes antes de entrar a la sala de intervenciones. La comunicación y el trabajo en equipo deben ser claros, las instrucciones sencillas, utilizar un volumen de comunicación adecuado, sin gritar y un esquema de comunicación en asa cerrada.

\section{Listas de chequeo y ayudas cognitivas}

Se recomiendan fuertemente su utilización, tanto para los abordajes iniciales como para el tratamiento de las dificultades inesperadas. 


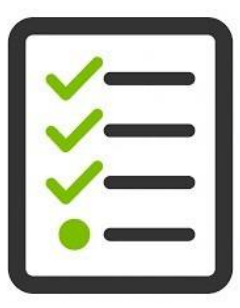

Se pueden consultar en los siguientes links : http://anestesiaclasa.org/guia--pacientes--covid--19/

https://static1.squarespace.com/static/5e 6613a1dc75b87df82b78e1/t/5e6d0530d 0ba

bc2b370bf29b/1584203289238/COVID --19 Airway--short.pdf

https://www.eamshq.net/images/INTUB ACIÓN_COVID 19 version_SP.pdf

\section{Posición adecuada del paciente}

Se recomienda el uso de rampa, posi ción de olfateo, entre otros, en ligera sobre-- elevación del tórax.

\section{Pre--oxigenación}

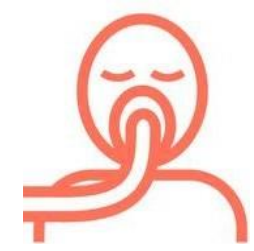

Con $\mathrm{FiO}_{2} 100 \%$ durante 3 a 5 minutos son mandatorias. La consideración de modos alternativos de administración de $\mathrm{O}_{2}$ (VNI) en bajo o alto flujo debe balancearse entre los beneficios que produce la técnica versus el grado de dispersión viral. La preoxigenación/ventilación debe ser llevada adelante por dos operadores, el primero sujeta la máscara facial en forma de "VE grip" y no en forma de "C" (técnica clásica), con ambas manos $y$ el segundo opera el circuito de ventilación si no está disponible el respirador. Un filtro anti vírico, humidificador debe interponerse entre la mascarilla facial y el circuito respiratorio, igualmente material de protección transparente podría colocarse encima del rostro del paciente.

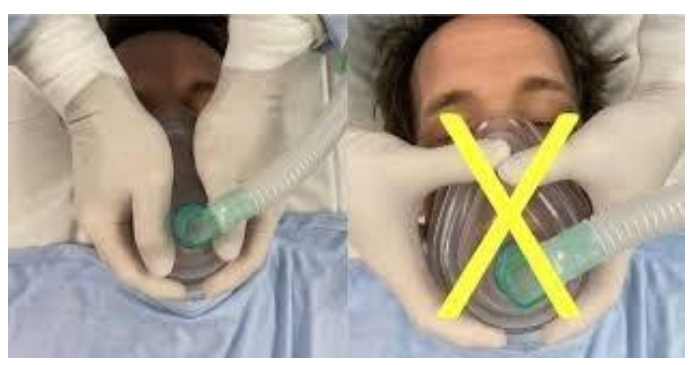

Un tercer operador puede ser necesario para la administración de drogas $\mathrm{y}$ revisión de monitoreo.

Si el paciente presenta intolerancia a la apnea de más de 30 segundos, o contraindicación específica a la succinilcolina, una ventilación manual gentil deberá aplicarse organizada con volúmenes bajos a frecuencia respiratoria alta con la técnica de dos operadores descrita anteriormente.

NODESAT (Nasal Oxygen During Efforts Securing a Tube) a $4 \mathrm{~L} / \mathrm{min}$ en paciente vigil y hasta $15 \mathrm{~L} / \mathrm{min}$ en paciente dormido administrado mediante bigotera es un modo de administración de oxígeno no invasivo (VNI) frío y seco (gas no acondicionado) que produce un efecto de "oxigenación apneica, estirando el período de apnea seguro" (PAS), permitiendo una laringoscopía e IOT más extendida en el tiempo antes del inicio de un episodio de desaturación arterial de $\mathrm{O}_{2}$. La utilización de flujos bajos es una ventaja, que supone menor grado de dispersión viral y en el balance riesgo vrs beneficio al mejorar el PAS podría utilizarse en pacientes severamente hipoxémicos, su principal desventaja es que el gas no acondicionado es fisiológicamente pobre.

No hay evidencia disponible de la capacidad de este modo (VIN) del nivel 
de dispersión viral, pero basados en los conocimientos del HFNO (High-Flow

Nasal Oxygen), parece poco probable.

NODESAT no está recomendada en el proceso de ISR para la IOT:

-Que no presenta dificultades desde el examen previo y se predice una IOT sencilla.

-Que no está cursando una hipoxemia actual.

-Que no se prevea la necesidad de un PAS largo o se asuma que el PAS va a ser corto

Finalmente existe un "gran debate acerca del HFNO" y la dispersión de gérmenes que pudiera derivar de su utilización, aún más con máquinas viejas. La contaminación bacteriana ha sido mejor establecida y sería baja, pero no se conoce en profundidad que podría pasar con los virus.

Razones adicionales que justifican no utilizarlo, son las enfermedades con requerimientos de IOT y ventilación mecánica en masa, ya que podrían demorar la indicación de IOT en pacientes a quienes subir un escalón de tratamiento es adecuado, en segundo lugar podría depletar los depósitos de oxígeno institucionales en una época donde las demandas serán previsiblemente más altas.

HNFO no esta recomendada en el proceso de ISR para la IOT

Algunos publicaciones provenientes de China alientan su utilización, como modo de VNI previo a la decisión de IOT, mientras que otras desde Inglaterra la desalientan.

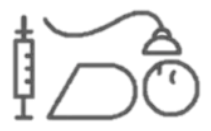

Inducción de secuencia
rápida

Concentrar esfuerzos en "seguridad", rapidez y eficiencia para lograr el "éxito en el primer intento", ya que los intentos múltiples podrían deteriorar al paciente y aumentar la contaminación del personal que interviene. La estrategia de intervención preferida es la "Inducción de Secuencia Rápida modificada" (ISRm) para evitar la ventilación, por posible causa de dispersión viral.

La presión cricoidea inicialmente podría aplicar a pacientes que presenten riesgo de aspiración del contenido gástrico, pero su continuidad es contextual y a juicio del operador, si interfiere con la ventilación o la IOT debe ser suspendida momentáneamente y reaplicada solo si se observa un episodio de regurgitación en marcha.

Si un dispositivo supraglótico (DSG) de 2 da generación está indicado, la maniobra de presión cricoidea debe ser descontinuada.

La selección del inductor podría variar según la severidad del cuadro clínico el estado mental y hemodinámico del paciente.

\section{Recomendaciones de medicación}

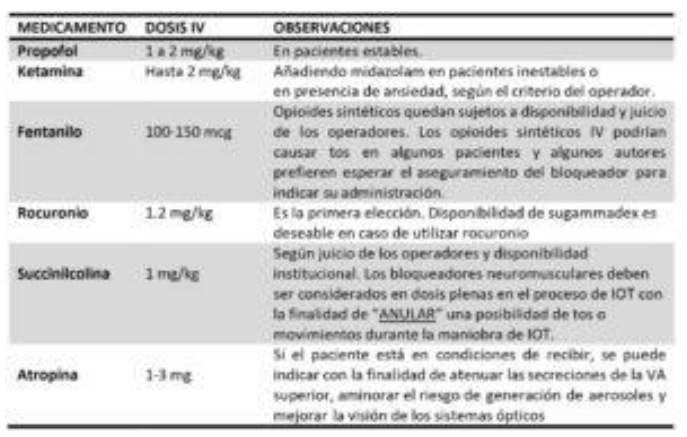

\section{Laringoscopía}

Videolaringoscopia (VL), Laringoscopia directa convencional 
(LDC) e IOT debe ser reservada al más experto disponible y su primer asistente debe ser otro operador especialista en anestesia y cuidados críticos con habilidades integrales similares en el manejo avanzado de la VA.

El VL con pala (hoja) hiperangulada, de bajo perfil y de pantalla separada es el dispositivo de primera elección (según disponiblidad) otros VL pueden ser utilizados. En caso de no haber completado la curva de aprendizaje o no disponer de experiencia con esta línea de dispositivos no se recomienda ejecutar técnicas que no son habituales al operador y es fuertemente aconsejado realizar las intervenciones con dispositivos que son familiares y con los que se tiene hábito.

Los coadyuvantes de la IOT pueden ser aplicados según juicio clínico del operador, maniobras laríngeas de manipulación externa, bouguies $\mathrm{o}$ bujías, estiletes maleables hiperangulados pueden ayudar a mejorar la oportunidad de éxito al primer intento.

Inmediatamente después de la IOT, clampear o sellar el tubo e inflar el neumotaponamiento y conectar el circuito respiratorio. La confirmación de la localización adecuada del TOT (tubo orotraqueal), se realiza mediante visión directa (VL) o Indirecta (LDC), por monitoreo de la capnografía (tres ondas consecutivas de morfología normal), luego de liberar el TOT, y valores adecuados de capnometría. Se debe prestar atención adicional para evitar la ventilación simple inadvertida, la identificación del número de TOT a nivel de incisivos superiores del paciente es un dato de aproximación útil, 23 y $21 \mathrm{~cm}$ para hombres y mujeres respectivamente. La inspección ocular del tórax puede ayudar, pero no se recomienda la auscultación. Finalmente se mantendrá la ventilación mecánica según los requerimientos de cada paciente en particular. Se puede instalar una sonda nasogástrica (SNG) en este momento si está indicado.

Para un eventual rescate de la VA difícil inesperada se prefieren DSG de 2da generación. Si la ventiliación con el DSG es exitosa, se sugiere completar la IOT con un bronco--fibroscopio o videoendoscopio desechable.

Ante una eventual necesidad de aspiración de secreciones, se debe disponer de un sistema cerrado con la finalidad de evitar mayor nivel de contaminación. Se recomienda utilizar TOT con sistema de aspiración subglótica si prevé intubación prolongada.

Tener disponible un kit para eFONA (acceso frontal en cuello) en caso de necesidad preferentemente con técnica de bougie, bisturí y TOT para un eventual rescate quirúrgico de la VA.

Evitar la topicalización de la $\mathrm{V}$ A, la intubación con bronco-fibroscopía o videoendoscopía en pacientes calificados como de VA estándar y dejar este recurso a lo estrictamente necesario (VA difícil anticipada) ya que podría aumentar la dispersión viral. En casos excepcionales se podría requerir de una VA quirúrgica primaria electiva para lo que se debería convocar al equipo quirúrgico correspondiente.

El control hemodinámico inmediato a la IOT es necesario y debe vigilarse a través de un monitoreo exhaustivo para una eventual asistencia con líquidos específicos o agentes vasoactivos para dicho tratamiento.

Ante un eventual manejo de pacientes C19 fuera de quirófano, o salas adecuadas, se deben evitar los modos de administración de VNI (CPAP, BPAP, 
EPAP, HFNO, THRIVE, POINT, O NODESAT) para prevenir la generación de aerosol del virus en la habitación y se debe preferir la IOT temprana bajo la utilización de escalas de detección precoz de deterioro respiratorio.

Se prefiere la IOT electiva (pro--activa) con escalas de detección e i ndicación de IOT temprana vs IOT de emergencia (salvataje), puesto que esta última habitualmente conlleva:

\section{-Elevado porcentaje de complicaciones}

-Múltiples intervenciones sobre la VA

-Mayor contaminación al staff

-Peores resultados en los pacientes

-Mayor consumo esperado de tiempo de ventilación mecánica

-Mayor tiempo de ocupación de camas en la unidad de cuidados críticos

-Malos resultados con mayor tendencia al colapso del sistema

\section{Reanimación cardiovascular avanzada}

Las compresiones torácicas en caso de RCP deberán realizarse con el paciente intubado $y$ el neumotaponamiento debidamente inflado para evitar la dispersión viral cerca del rostro del operador de la VA.

Todas las herramientas utilizadas deben ser colectadas en bolsas de doble sello e iniciar un proceso de desinfección $\mathrm{y}$ desecho según técnica. Los equipos, superficies, y todo material potencialmente contaminado debe ser exhaustivamente descontaminado con la finalidad de evitar una contaminación indirecta al personal.
Consultar guías de reanimación cardiovascular avanzada CLASA.

\section{La extubación}

La extubación es un proceso donde hay que mantener los principios de cuidados estrictamente vigentes, el paciente podría toser o eliminar secreciones exponiendo al personal a contaminación. Es importante que el proceso sea llevado adelante con el paciente debidamente analgesiado, oxigenado y con la vejiga vacía con la finalidad de no promover cuadros de excitación derivados de estas causas. También el paciente podría ser sujetado en sus extremidades para evitar movimientos involuntarios. Una vez decidida la intervención se deben colocar gasas húmedas alrededor de la boca del paciente, también se podría cubrir con un material transparente e impermeable sobre la cara del mismo y realizar las maniobras bajo esa protección. Si procede, se puede realizar aspiración de secreciones y la extracción del tubo se debe realizar junto al circuito de respiración para minimizar la dispersión viral. El soporte inmediato con MFS y $\mathrm{O}_{2}$ suplementario se debe administrar si está disponible.

El paciente se debe trasladar con una mascarilla facial protectora y oxígeno suplementario administrado por bigotera nasal.

La protección del personal y del ambiente debe ser la máxima disponible en este momento, y todos los materiales de la sala deben ser debidamente protegidos, descontaminados y desinfectados según técnica.

\section{Resumen y puntos claves}

--Seguridad para el personal de salud y los pacientes 


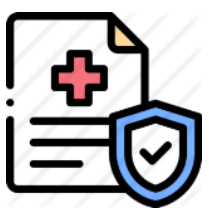

--Evitar intervenciones con técnicas que no son familiares al operador

--Realizar intervenciones a tiempo oportuno, sin prisas, ni demoras Video Resumen

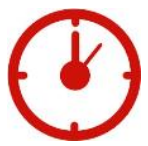

COVID/Induction in the operating theatres at Sir Charles Gairdner Hospital, $\quad$ Perth, Australia. https://www.youtube.com/wa tch? feature $=$ youtu.be \&v $=\mathrm{OF} 6 \mathrm{dMhRvD}$ $\underline{8 \mathrm{M} \& a p p=\text { desktop }}$

\section{Referencias}

- Outbreak of a new coronavirus: what anaesthetists should know. Publicado en marzo de 2020. British Journal of Anesthesia (BJA). https://www.ncbi.nlm.nih.gov/p ubmed/32115186

- Expert Recommendations for Tracheal Intubation in Critically ill Patients with Novel Coronavirus Disease 2019. Chinese Society of Anaesthesiology. Chinese Medical Sciences Journal in 2020. Published online 2020/2/27 (PDF)

- Airway Management/Covid19. Rev 1.1 CA. Publicado marzo de 2020. a Sociedad Italiana de Anestesia, Analgesia, Reanimación y Terapia Intensiva SIAATRI Gestione Vie Aeree (GVA) Italia. Grupo Italiano de manejo de la VA. https://www.esahq.org/esa--news/covid--19--airway--management/ (

- Clinical Guidance Airway management, COVID--19 Airway Management Principles. Publicado marzo de 2020. Real College of
Anaesthetists (RCoA) \& Faculty of Intensive Care of Medicine (FICM), Intensive Care Society (ICS) \& Association of Anaesthetists (AofA) UK. https://icmanaesthesiacovid--19.org/airway--management-guidance (HTML)

- Pasos para ponerse el equipo de protección personal (EPP) incluida la bata. Organización Panamericana de la Salud (OPS), Organización Mundial de la Oficina las Américas para OMS). https://www.who.int/csr/resour ces/publications/PPE EN A1sl.pdf?ua $=1$. https://www.who.int/activities/stre ngthening--public--health--laboratory-services/videos

- Video Tutorial para colocacion y extracion de PPE en paciente COVID19+. Servicio de Anestesiología y Reanimación del Hospital Universitario Marquéz de Valdecilla, $\begin{array}{cccc}\text { realizado } & \text { en } & \text { el } \\ \text { Hospital } & \text { vitual } & \text { Vald }\end{array}$ ecilla. https://www.youtube.com/watch ? $\mathrm{v}=0 \mathrm{u} 6 \mathrm{EvyzMsVE}$

- Critical Care Airway Management, (CCAM.UK). The Difficult Airway Rescue Techniques (DART) Course from the UK. The Severn Airway Training Society (SATS). https://www.ccam.net.au/hand book/difficult--airway--algorithms--and--checklists/ (HTML)

- COVID airway management: SAS consensus statement. Safe Airway Society. The interprofessional airway society for Australia and New Zealand. https://first10em.com/covid--airway--management--sas--consensus--statement/ (HTML)

- Society for Airway Management. DocMatter Community (SAM) USA. Únicamente con login

- Airway Matters, Future Learns UK. University College London Hospital (UCLH). https://www.futurelearn.com/ courses/airway--matters/1/ (HTML)

- An international survey about rapid sequence intubation of 10,003 
anaesthetists

and $\quad 16$

ay

6
/10.1111/anae.14867 (HTML)

- Aerosol Generating Procedures and Risk of Transmission of Acute Respiratory Infections to Healthcare Workers: A Systematic Review. April 2012 | Volume 7 | Issue 4 | e35797. PLoS ONE $\mid$ www.plosone.org

- COVID Induction in the operating theatres at Sir Charles Gairdner Hospital,

Perth,Australia. https://www.youtube.c om/watch?feature $=$ youtu.be \&v $=$ OF6d MhRvD8M\&app $=$ des ktop

Intubation and Ventilation amid the COVID-19 Outbreak. Wuhan's Experience.
Downloaded from anesthesiology.pubs.asahq.org by guest on 03/21/2020 (ㄴML)

Correspondencia al autor

\section{Guillermo Navarro}

navarroguillermo88@yahoo.com

Coordinador del Capítulo de Vía Aérea Difícil de la Confederación Latinoamericana de Sociedades de Anestesia (CLASA).

Director del Grupo de Entrenamiento en Via Aérea Latinoamérica (EVALa).

Miembro del Comite de Redacción de AnestesiaR.

Miembro de Grupo Asesor del Proyecto for Universal Management of Airway (PUMA).

Aceptado para el blog en abril de 2020 